\title{
Possibility of applying a slider-crank mechanism to design sugarcane buds cutter
}

\author{
Mahmoud W. A.*, Elkaoud N. S., Abu El-Maaty A. E. \\ Faculty of Agricultural Engineering, Al-Azhar University (Assiut Branch), Assiut, Egypt
}

\begin{abstract}
The cutting forces estimation is one of the most important design criteria necessary for the optimal manufacture of sugarcane buds cutting machines. This research was conducted to investigate the possibility of applying a slider-crank mechanism to design a sugarcane buds cutter and estimating the power required to operate the mechanism. Random samples of Egyptian sugarcane variety C-9 (At the average moisture content of $76.33 \%$ wet basis) were used to determine cutting forces under three-blade sharpening angles 15,30 and $45^{\circ}$ at the different positions of the cane stick. The results indicated that the cutting force increased by increasing the blade sharpening angle at all positions of the cane stalks. The maximum value of cutting force was $138.1 \mathrm{~kg}$ at the node position and bottom of cane stalks using a blade sharpening angle of $45 \mathrm{o}$. The minimum value of cutting force was $77.5 \mathrm{~kg}$ at the internode position and top of the cane stick using the knife chamfer angle of $15 \mathrm{o}$. A sliding-crank mechanism can be applied in the design of the sugarcane stalk buds cutting unit. Under experimental conditions, it is possible to use an engine of at least $0.21 \mathrm{hp}$ to operate the mechanism.
\end{abstract}

Keywords: sugarcane, cutting force, buds cutter, sliding-crank mechanism.

*Corresponding author: Mahmoud W. A., 


\section{Introduction}

Sugarcane (Saccharum officinarum L.) is considered the main source of sugar production in Egypt and many countries around the world. The area of sugar cane in Egypt reached up to 332 thousand feddan (feddan $=4200 \mathrm{~m}^{2}=0.420$ hectares $=1.037$ acres), with an average production of $48.6 \mathrm{Mg} /$ feddan, (CCSC, 2020). The transplanting technique has been applied in several countries for reducing the duration of the sugarcane production season. Sugarcane seedling planting in the nursery is done using single buds, the sugarcane buds mean excised axillary buds from cane stalk, these buds are less in size, easily transportable, fast-growing, and more economical seed material. Traditional hand-held cutting tools of sugarcane buds create a strain on the hands and thumb, cause wastage, and damage with slanting cuts, and are incapable of dealing with hard plant grafting. Sugarcane transplanting has been recommended as an alternative planting method for saving a considerable part of irrigation water that determines the expansion of the agricultural areas in the country. Drees (2005) recommended that sugarcane transplanting could be used as an alternative method for the sugarcane seedlings. The application of the transplanting technique to replace the traditional planting of sugarcane saves up two months of the crop production season. Mahmoud (2016) mentioned the feddan is needed about $1600 \mathrm{~kg}$ from sugar cane stalks suitable for agriculture for obtaining bud sets. Galal (2016) reported that, if bud chips are used saving about $97 \%$ of cane by weight is economical in terms of the crop cultivation costs. It also saves several thousand tons of raw material that could be used for extracting sugar. Abdel Mawla et al. (2014a) reported that the transplanting sugarcane saves a considerable amount of irrigation water determined as $2000 \mathrm{~m}^{3} / a c r e$ and the quantity of seed consumed when applying the transplanting technique is largely less than that of the traditional method. Ragupathi et al. (2017) mentioned that the traditional tools used for bud chipping sugar cane are unsafe, messy, minimum productive, and need skill and training, the risk of injury is also too high, this necessitates the development of an automated sugarcane bud chipping machine. Suraj et al. (2016) designed and fabricated a pedal-operated sugarcane bud chipping machine where the sugarcane is fed to the cutting region manually, when the operator starts pedaling the cutting action starts and the sugarcane buds are cut along with the stalk. Abdel Mawla et al. (2014b) performed tests on the Egyptian sugar cane variety $\mathrm{C} 9$, and they found that surface hardness at the internodes was $325 \mathrm{~N}$ of samples taken from the newly planted crop, $452 \mathrm{~N}$ for the $1^{\text {st }}$ Raton, 515 for the $2^{\text {nd }}$ Raton, $601 \mathrm{~N}$ for the $3^{\text {rd }}$ Raton and $607 \mathrm{~N}$ for the $4^{\text {th }}$ Raton. Abarna et al. (2017) designed machine cutting buds from sugarcane stalk, that consists of a platform, hemisphere chipping knife, sphere chipping knife, linkage system, and handle. This machine used to chip out the bud from sugarcane for sowing purpose and for tissue culture that. Also, this machine can remove buds from the 
sugarcane for the plantation purpose to minimize losses as well as time, money, and seeds, with this implement. Mahesh et al. (2017) mentioned that the bud chip technology could be one of the most viable and economical alternatives for a manually operated machine and can be converted manually operated machines into automatic ones by using an electric motor. Mathanker (2015) investigated the influences of the cutting speed and blade oblique angle on the cutting energy with an impact type cutting mechanism and found that the specific cutting energy increases with the cutting speed. Igathinathane et al. (2010) reported that the shearing was an energy-efficient method of size reduction and was achieved by devices that used knives, shear bars, and linear knife grids. Taghinezhad et al. (2013) studied using a linear blade cutting and UTM (Unevrsal Teste Material) device to determine the shearing stress and energy characteristics for applying force on sugarcane stalks through a blade device. Mean specific cutting energies of cane stalks at low, medium, and high levels of moisture content were $34.071,28.339$ and 16.297 $\mathrm{kN} / \mathrm{m}$ and for ultimate stress were 7.086 , 2.586 and $1.656 \mathrm{MPa}$, respectively. Taghijarah et al. (2011) reported that the cutting forces of the serrated blades were smaller than those of the slippery blade, cutting velocity and cutting position on the rape stem had the greatest effects on the cutting forces, which shown as the decrease of the cutting forces with the increasing of the cutting velocity and the raising of cutting position on the rape stem above the ground. When the singlestalk was cut with smooth-edge, short- blade, and double blades in the form of shearing, the maximum cutting drive force reached the maximum value of $0.4512 \mathrm{kN}$; when the single-stalk was cut with serrated-edge, long-blade and single blade in the form of extrusion, the maximum cutting drive force reached the minimum value of $0.2114 \mathrm{kN}$; when the single-stalk was cut with smooth-edge, short-blade and single blade in the form of extrusion (Shen et al., 2014). The slider-crank mechanism is a specific type of linkage converting translational and rotational motions together. The importance of this mechanism has been well recognized in industrial applications such as combustion engines (Chang et al., 2013). The cutting velocity in the cutting machines by reaction forces in joints, and required effective internal torque are influenced by the parameters of the mechanism. Some of these parameters include crank length and angular velocity, connecting rod length, and the crank to connecting rod length ratio, therefore carefully, and optimally selecting such parameters is of great importance (Naeeni et al., 2019). Accordingly, The main objective of this research is to estimate of maximum cutting forces required to cutting buds of sugar cane stalks which use to establish the sugarcane seedlings nursery where includes a healthy bud and root band.

\section{Materials and methods}

\subsection{Sugarcane stalks characteristics}

The source of the sugarcane stalks used in this research were brought from the 
Sugarcane Crops Research Institute, before any treatment or measurement and Agricultural Research Center, Shandawil, kept inside polyethylene bags in a Sohag, Egypt. The stalks were selected refrigerator at $4{ }^{\circ} \mathrm{C}$ before carrying out from the field of the second season when harvest at nine months old. The samples were randomly selected, cleaned, and leaf-sheaths were manually removed the measurements. Total length stalks (L) were divided into three positions (top, middle, and bottom) as shown in Figure (1).

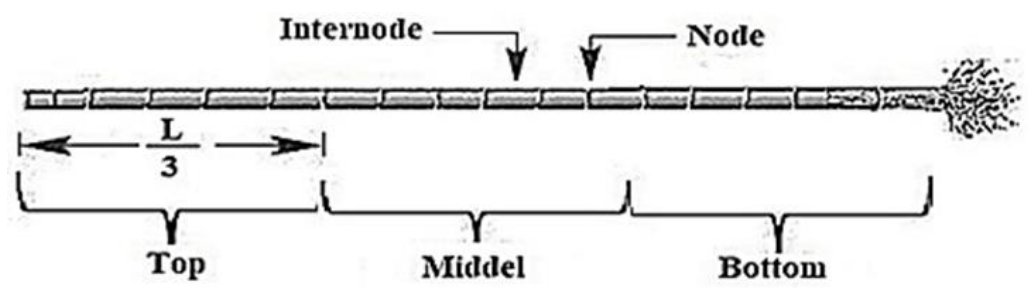

Figure (1): Sketch of sugarcane-stalk components.

Each part was divided into samples containing (internode and node). The determination of characteristics was carried out during summer 2021 in the Faculty of Agricultural Engineering, Al-
Azhar University, Assiut, Egypt. Characteristics of sugarcane C-9 variety stalk before buds separation to use for obtaining of buds are presented in Table (1).

Table (1): Characteristics of sugarcane C-9 variety stalk before buds separation.

\begin{tabular}{|l|c|c|}
\hline Characteristics & Average & Standard deviation \\
\hline Stalk length "L", cm & 295.6 & \pm 9.13 \\
\hline Stalk diameter "D", cm & 2.36 & \pm 0.15 \\
\hline Stalk mass "M", kg & 1.98 & \pm 0.11 \\
\hline The number of buds on the stalk & 16.54 & \pm 1.80 \\
\hline
\end{tabular}

\subsection{Samples}

Random samples of 30 sugarcane stalks are used to preparation of types samples internode (IN) and node (N), which manually cutting with a sharp knife to obtain samples with length $15 \mathrm{~cm}$, infected samples were excluded. Then the diameter of the samples was measured at the cut position. To determine the average moisture content of the stalks, some random samples were weighed, oven-dried at $103{ }^{\circ} \mathrm{C}$ for $72 \mathrm{~h}$ (Taghijarah et al., 2011) and weighed again to determine the moisture content. The average moisture content of the specimens was $76.33 \%$ wet basis. Figure (2) shows samples internode (IN) and node $(\mathrm{N})$ of sugarcane before conducting laboratory tests. 


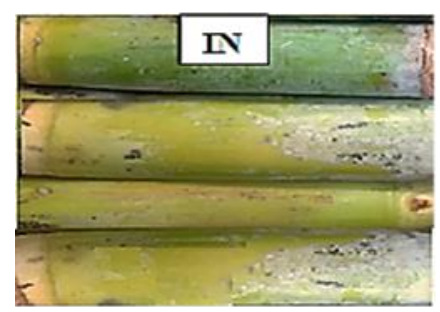

Internode

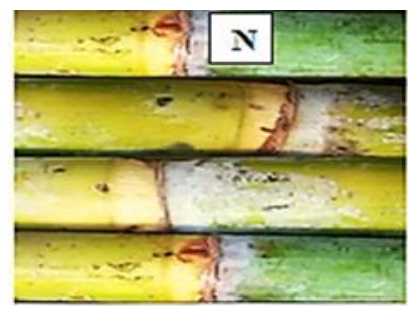

Node

Figure (2): Photographs of the samples sugar cane buds.

\subsection{Cutting forces measurement}

The cutting force was measured by using a digital universal material tester as shown in Figure (3). The specifications of the device were as follows: Model No: MT 2021 with an accuracy is $0.1 \mathrm{~kg}$. Laboratory tests were carried out during summer 2021 in the Faculty of Agricultural Engineering, Al-Azhar University, Cairo, Egypt. The cane samples diameter was measured by a digital Vernier-caliper with an accuracy of $0.01 \mathrm{~mm}$. Then, cutting force was applied to the cane stalk samples by the cutting blades. The blade was fixed at the crosshead of the compression material tester, and a sample was held on the counter shear support. The maximum cutting force that appeared on the digital screen, which led to cutting the sample in half, was recorded.

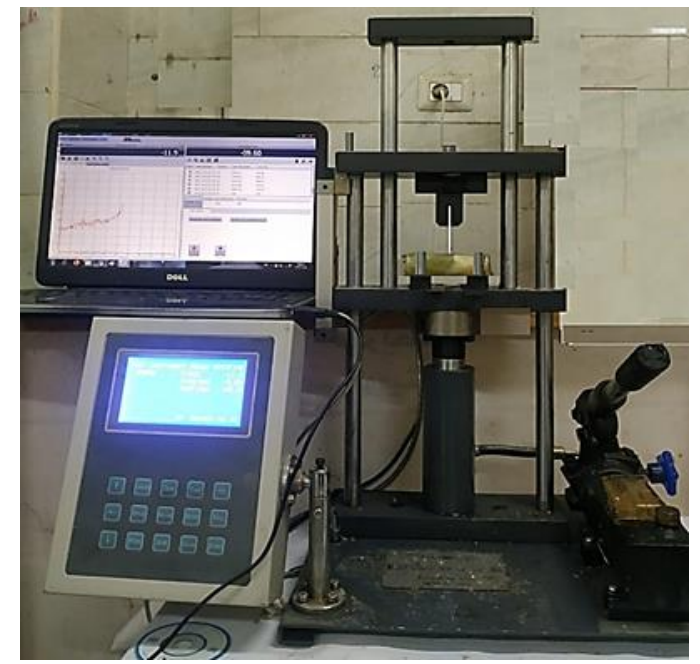

Figure (3): Photograph of digital universal material tester. 


\subsection{Cutting blades}

Three sharpening angles of cutting blades of 15,30 and $45^{\circ}$ (single bevel) were used in this study with perfectly straight, with a smooth surface edge, fabricated in the workshop Faculty of Engineering of Assiut University, Assiut, Egypt by using material structure stainless steel (Grade 304). The dimensions of these blades are $100 \mathrm{~mm}$ of height, $75 \mathrm{~mm}$ of width, and 1.5 of thickness. Figure (4) shows the schematic diagram of the cutting blades. The blades are sharpened after each set of experiments to avoid errors caused by a blunt cutting-edge face.

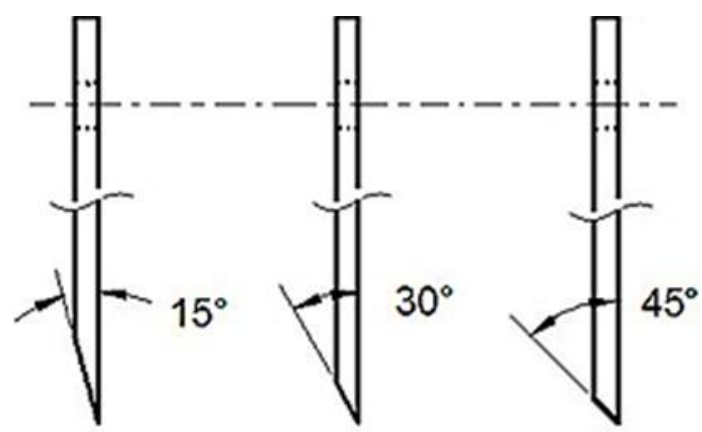

Figure (4): Side view of cutting blades.

2.5 The kinematic analysis of the cutting unit (A slider-crank mechanism)

The traditional mechanism which is widely used in internal combustion engines is a concentric slider-crank mechanism. This mechanism has one degree of freedom, that is, a constrained mechanism. In considering the kinematic analysis of the slider-crank mechanism, it is necessary to determine the displacement of the slider and then its corresponding velocity and acceleration. For this purpose, displacement of the piston can be defined as a function of the crank's angular position in Figure (5) This mechanism can be used as an effective cutting unit, which is the basis for an optimal design of the buds cutting machine. The cutting process is carried out by a fixed of two parallel blades in front of the slider, the distance between them is the length of the bud. To design a machine for running with an electric motor thus, it was necessary to determine the capacity of the motor to be fitted based on the maximum cutting force that was measured to separate the buds of the sugarcane stalks.

\section{Let that:}

- The connecting rod rotates with an angular velocity of $\omega \mathrm{rad} / \mathrm{s}$, and the crank turns through an angle $\theta$ from the center.

$\circ \mathrm{X}$ is the displacement of a reciprocating body $\mathrm{C}$ (Cutting blades) after time $\mathrm{t}$ seconds, during 
which the crank has turned through $\bigcirc \varphi$ is the inclination of connecting rod an angle $\theta$. to the line of stroke BO.

$\circ \quad l$ is the length of connecting rod $\bigcirc \mathrm{n}$ is the ratio of the length of between the centers.

o $r$ is the radius of the crank. connecting rod to the radius of crank $=\frac{l}{r}$

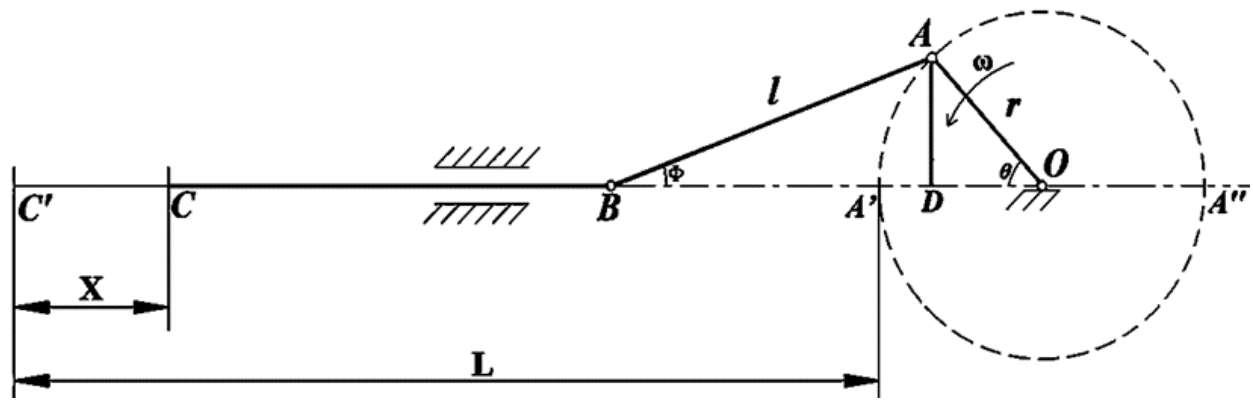

Figure (5): Schematic motion of crank and connecting rod for the cutting mechanism.

2.5.1 Velocity of the reciprocating body C (Cutting blades)

From Figure (5), $X=C^{\prime} C=O C^{\prime}-O C=\left(C^{\prime} A^{\prime}+\right.$ $\left.A^{\prime} O\right)-(C B+B D+D O)$ $X=L+r-(C B+I \cos \Phi+r \cos \theta)$ $X=L+r-C B-I \cos \Phi-r \cos \theta$

But from Figure (5); $L-C B=I$

So; $X=I-I \cos \Phi+r-r \cos \theta=I(1-\cos \Phi)+r$

$$
\begin{aligned}
& (1-\cos \theta) \\
X & =r(1-\cos \theta)+I(1-\cos \Phi) \\
= & r\left[(1-\cos \theta)+\frac{l}{r}(1-\cos \Phi)\right] \\
\therefore X= & r[(1-\cos \theta)+n(1-\cos \Phi)] \ldots . .
\end{aligned}
$$

From $\triangle \mathrm{ABD}$ and $\triangle \mathrm{ADO}$;

$$
\begin{gathered}
A D=l \sin \Phi=r \sin \theta \\
\text { or; } n=\frac{l}{r}=\frac{\sin \theta}{\sin \Phi} \quad \therefore \quad \sin \Phi=\frac{\sin \theta}{n}
\end{gathered}
$$

But, $\cos \Phi=\left(1-\sin ^{2} \Phi\right)^{0.5}$

$$
\therefore \quad \cos \Phi=1-\left(\frac{\sin ^{2} \theta}{n^{2}}\right)^{0.5}
$$

By using the binomial expansion of:

$$
\begin{aligned}
(1-x)^{n}= & 1-n x+\frac{n(n-1)}{2 !} x^{2}-\frac{n(n-1)(n-2)}{3 !} x^{3}+\ldots \\
& \therefore \cos \Phi=1-0.5\left(\frac{\sin ^{2} \theta}{n^{2}}\right)+\ldots \\
& \therefore \cos \Phi=1-\left(\frac{\sin ^{2} \theta}{2 n^{2}}\right) \ldots \ldots . .(2)
\end{aligned}
$$

Substitute in equation (1) by (2);

$$
\begin{gathered}
X=r\left[(1-\cos \theta)+n\left(\frac{\sin ^{2} \theta}{2 n^{2}}\right)\right] \\
\text { By derivative } X \text { with respect to } \theta: \\
\frac{d x}{d \theta}=r\left[\sin \theta+\frac{1}{2 n}(2 \sin \theta \times \cos \theta)\right] \\
\frac{d x}{d \theta}=r\left[\sin \theta+\frac{\sin 2 \theta}{2 n}\right]
\end{gathered}
$$

Therefore, the velocity of the reciprocating body (Cutting blades) can be obtained by the displacement derivative $\mathrm{X}$ with respect to time $(\mathrm{t})$ :

$$
\begin{aligned}
V_{c} & =\frac{d x}{d t}=\frac{d x}{d \theta} \times \frac{d \theta}{d t}=\frac{d x}{d \theta} \times \omega \\
\therefore \quad V_{c} & =\omega r\left[\sin \theta+\frac{\sin 2 \theta}{2 n}\right] \ldots \ldots \ldots .
\end{aligned}
$$


2.5.2 Acceleration of the reciprocating body C (Cutting blades)

The acceleration of the reciprocating body (Cutting blades) can be obtained by the velocity derivative $V_{c}$ with respect to time $(\mathrm{t})$ :

$$
\begin{array}{r}
A_{c}=\frac{d V_{C}}{d t}=\frac{d V_{C}}{d \theta} \times \frac{d \theta}{d t}=\frac{d V_{C}}{d \theta} \times \omega \\
A_{c}=\omega^{2} r\left[\cos \theta+\frac{2 \times \cos 2 \theta}{2 n}\right] \\
\therefore \quad A_{c}=\omega^{2} r\left[\cos \theta+\frac{\cos 2 \theta}{n}\right] \ldots \ldots .(5)
\end{array}
$$

The power is calculated based on the maximum speed and maximum acceleration of the cutting blades:

$\therefore V_{c}\left(\right.$ Max.at $\left.\theta=90^{\circ}\right)=\omega r[1+0] \ldots$ (6)

$\therefore A_{c}\left(\operatorname{Max}\right.$. at $\left.\theta=0^{\circ}\right)=\omega^{2} r\left[1+\frac{1}{n}\right]$..

\subsubsection{The power required}

By using equations (6) and (7), the power required can be estimated by the following equation:

$$
\begin{array}{r}
\text { Power }=\left(\text { Mass } \times A_{c}\right) \times V_{c} \\
\text { Power }=\text { Mass } \omega^{3} r^{2}\left(1+\frac{1}{n}\right) \\
\therefore \text { Power }=M \cdot \omega^{3} \cdot r^{2}\left(1+\frac{r}{l}\right) \ldots \ldots
\end{array}
$$

2.6 Possibility of applying the mechanism as an effective mechanical component of buds cutting machine

The bud chips recommended in the previous literature for transplanting sugarcane seedlings are not more than 5 $\mathrm{cm}$ long and contain one bud. The cutting mechanism to separate buds can be suggested with two adjacent blades, the distance between them $5 \mathrm{~cm}$, and connected to the front of the sliding part as showing in Figure (6).

\subsection{Variables of experiments}

To estimate of maximum cutting forces required to separate the buds of sugar cane stalks the most important variables have been taken into consideration to realize the purpose of this research. Variables of experiments are as following:

\subsubsection{Cutting position}

Three cutting positions have been determined on the cane stalk. Total length stalks (L) were divided into three positions (top, middle, and bottom).

\subsubsection{Type of samples}

Cane samples were classified into two types (internode and node).

\subsubsection{Cutting blades angle}

The cutting process was done using three sharpening angles of blades 15, 30 and $45^{\circ}$ (single bevel).

\subsection{Data analysis}

The data was statistically analyzed using the computer MSTAT-C statistical analysis package according to Freed et al. (1989). The least significant differences (LSD) test at a probability 
level of 0.05 was manually calculated to of variance (ANOVA) was used to compare the differences among means. compare the within means variance to the For statistical analysis, one-way analysis between-means variance.

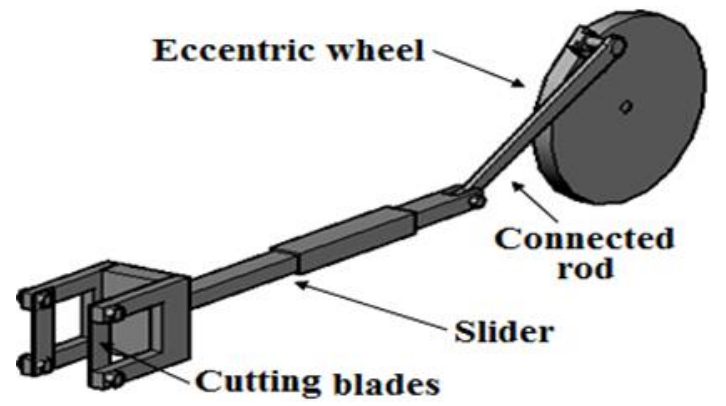

Figure (6): Effective mechanical component of buds cutting machine using the slider-crank mechanism.

\section{Results and Discussion}

\subsection{Sugarcane stalk diameters}

The diameters were measured at the same cutting positions. Table (2) shows a summary of the data obtained. The results obtained in Table (2) showed that the diameters at the top (internode and node), middle (internode and node) and bottom (internode and node) of the cane stalk ranged from 22 to $35.5,25$ to 33.5 , 24.5 to $36.25,25.5$ to $32.05,27$ to 35.74 and 25.75 to $36 \mathrm{~mm}$ with the mean values $\pm \mathrm{SD}$ of $29.45 \pm 4.5,29.15 \pm 2.54$, $30.4 \pm 4.68,28.26 \pm 2.97,29.27 \pm 2.67$ and $28.86 \pm 2.92 \mathrm{~mm}$ respectively.

\subsection{Effect of blade sharpening angle on average cutting forces}

The cutting force is not a constant value, but it varies according to the conditions of the cutting process, the position of cutting and blade sharpening angle are the most important factors that affect the cutting force required for sugar cane stalks. Figure (7) shows the effect of blade sharpening angle on average cutting forces at the different positions of the cane stalks. The results indicated that the cutting force increased by increasing the blade sharpening angle at all positions of the cane stalks. This may be due to the increased force required to overcome the lateral friction force with the large blade sharpening angle during the cutting process. At the internode positions; when the blade sharpening angle increased from 15 to $45^{\circ}$, the average $( \pm$ SD) cutting forces increased from $68.35 \pm 5.56$ to $87.21 \pm 9.68$, from $76.56 \pm 10.10$ to $89.55 \pm 6.47$ and $91.8 \pm$ 5.77 to $100.61 \pm 7.44 \mathrm{~kg}$ at the top, middle and bottom of cane stalk respectively. 
Table (2): The diameters of sugarcane C-9 variety stalk before buds separation.

\begin{tabular}{|l|l|c|c|c|c|c|}
\hline \multirow{2}{*}{ Cutting positions } & \multirow{2}{*}{ Type of Samples } & \multicolumn{5}{|c|}{ Average diameters (mm) } \\
\cline { 3 - 7 } & & Maximum & Minimum & Average & S.D. & C.V.\% \\
\hline \multirow{2}{*}{ Top } & Internode & 35.50 & 22.00 & 29.45 & 4.50 & 15.27 \\
\cline { 2 - 7 } & Node & 33.50 & 25.00 & 29.15 & 2.54 & 8.70 \\
\hline \multirow{2}{*}{ Middle } & Internode & 36.25 & 24.50 & 30.40 & 4.68 & 15.39 \\
\cline { 2 - 7 } & Node & 32.05 & 25.50 & 28.26 & 2.97 & 10.49 \\
\hline \multirow{2}{*}{ Bottom } & Internode & 35.74 & 27.00 & 29.27 & 2.67 & 9.13 \\
\cline { 2 - 7 } & Node & 36.00 & 25.75 & 28.86 & 2.92 & 10.12 \\
\hline
\end{tabular}

At the node positions; when the blade from $91.48 \pm 5.77$ to $107.25 \pm 7.77$ and sharpening angle increased from 15 to $105.2 \pm 13.92$ to $134.41 \pm 3.93 \mathrm{~kg}$ at the $45^{\circ}$, the average cutting forces increased top, middle and bottom of the cane stalk from $78.96 \pm 10.39$ to $91.75 \pm 10.43$, respectively.
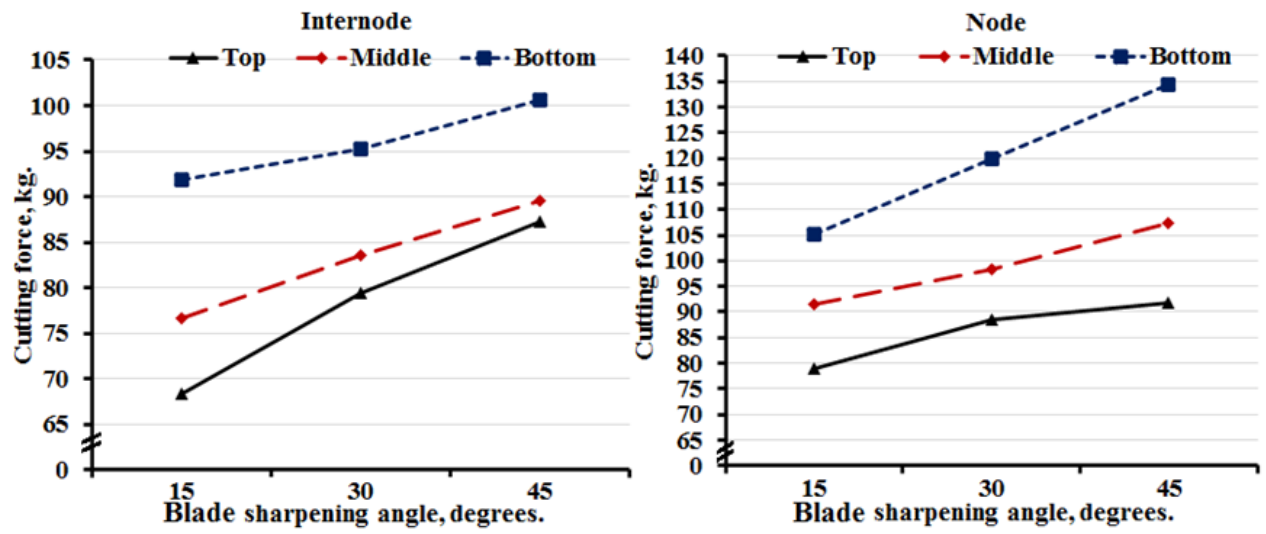

Figure (7): Effect of blade sharpening angle on average cutting forces at the different positions of the cane stalks.

\subsection{Effect of cutting positions on cutting forces}

Figure (8) shows the effect of cutting positions for cane stalks on cutting forces. The results showed that the cutting forces required at cane stalk bottom are often greater than that required at any other position using any blade sharpening angle. While the cutting forces required are least at cane stalks top position. Also, the results indicated that the cutting force required at the node positions is often greater than that required at the internode positions using any blade sharpening angle, this may be due to the anatomical differences between nodes and internodes of sugarcane stalks. The maximum value of average cutting force was $134.41 \mathrm{~kg}$ at node bottom position of cane stalks using blade sharpening angle of $45^{\circ}$. While the 
minimum value of the average cutting position of cane stalks using a blade force was $68.35 \mathrm{~kg}$ at the internode top sharpening angle of $15^{\circ}$.

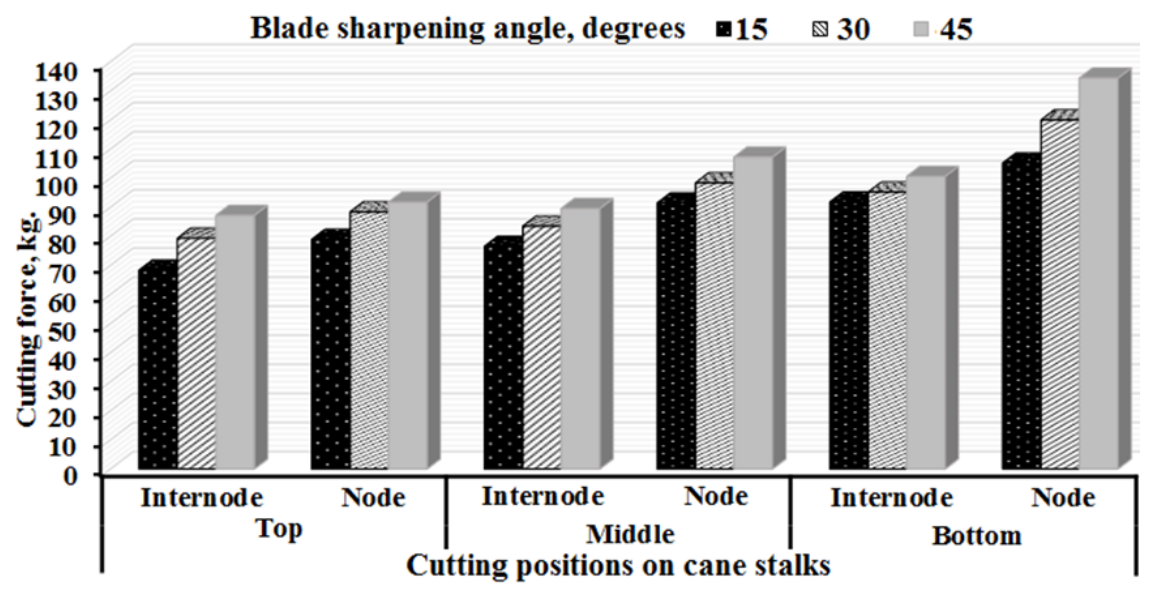

Figure (8): Effect of cutting positions for cane stalks on cutting forces.

\subsection{The maximum cutting forces}

Table (3) shows the maximum cutting forces obtained under the experimental conditions. The results indicated that the maximum value of the cutting force was
$138.1 \mathrm{~kg}$ at the node bottom position of the cane stalk using a blade sharpening angle of $45^{\circ}$. Thus, the power unit required for the operation of the machine can be estimated using the maximum cutting force.

Table (3): Maximum cutting forces under the experimental conditions.

\begin{tabular}{|c|c|c|c|c|c|c|}
\hline \multirow{2}{*}{ Blade sharpening angle } & \multicolumn{6}{|c|}{ The maximum cutting forces (kg) } \\
\cline { 2 - 7 } & \multicolumn{2}{|c|}{ Top } & \multicolumn{2}{c|}{ Middle } & \multicolumn{2}{c|}{ Bottom } \\
\cline { 2 - 7 } & IN & N & IN & N & IN & N \\
\hline $15^{\circ}$ & 77.5 & 90 & 95.1 & 97.9 & 100 & 114.5 \\
\hline $30^{\circ}$ & 87 & 98 & 98 & 111 & 110.5 & 122 \\
\hline $45^{\circ}$ & 98.7 & 105 & 102.5 & 116.6 & 115.5 & 138.1 \\
\hline
\end{tabular}

\subsection{Data analysis}

The results of ANOVA (LSD value at 0.05) indicated that the effect of blade sharpening angle on cutting force was significant, highest mean value of cutting force was $101.79 \mathrm{~kg}$ by using the blade sharpening angle $45^{\circ}$, while the lowest mean values were $85.56 \mathrm{~kg}$ by using blade sharpening angle $15^{\circ}$. Also, the effect of stalk position on cutting force was significant, the highest mean value of cutting force was $108.4 \mathrm{~kg}$ at the bottom position of stalks. The results also 
demonstrate statistically significant differences in the effect of type of samples (Internode and node) on cutting force, the maximum mean value of cutting force was $101.87 \mathrm{~kg}$ at internode position of stalks. In addition, the interaction analysis between types of samples (Internode and node) and positions of stalks showed significant differences in their effect of mean values of cutting force, where the highest mean value was $120.21 \mathrm{~kg}$ in the position of node bottom stalks. The results of ANOVA for the effect of blade sharpening angle, stalk position, and type of samples (Internode and node) on the cutting force of sugar cane stalks are listed in Table (4).

Table (4): Result of analysis of variance for effect of blade sharpening angle, stalk position, and type of samples (Internode and node) on cutting force of sugar cane stalks.

\begin{tabular}{|c|c|c|c|c|}
\hline \multicolumn{4}{|l|}{ Treatment } & L.S.D. (0.05) \\
\hline Sharpening angle: & $15^{\circ}$ & $30^{\circ}$ & $45^{\circ}$ & \multirow{2}{*}{3.54} \\
\hline Mean & 85.56 & 94.14 & 101.79 & \\
\hline Position on stalks: & Top & Mid. & Bot. & \multirow{2}{*}{3.03} \\
\hline Mean & 82.34 & 91.12 & 108.04 & \\
\hline Type of samples: & \multicolumn{2}{|c|}{ Internode } & Node & \multirow{2}{*}{2.18} \\
\hline Mean & \multicolumn{2}{|c|}{85.79} & 101.87 & \\
\hline \multicolumn{5}{|c|}{ Position on stalks $\times \quad$ Type of bud } \\
\hline \multirow{2}{*}{ Mean } & 78.31 & 83.21 & 95.87 & \multirow[t]{2}{*}{3.78} \\
\hline & 86.37 & 99.04 & 120.21 & \\
\hline
\end{tabular}

3.6 Estimation of the power required to operate the effective mechanical component of buds cutting machine

The power required to operate the proposed cutting unit was calculated according to the following significant assumptions:

- The maximum single cutting force is $138.1 \mathrm{~kg}$ for bottom sugar cane stalks this value is doubled in case of double cutting with two blades.

- Radius of crank rotation $=80 \mathrm{~mm}$.

- Length of connecting rod $=240 \mathrm{~mm}$.

- The rotation speed of the crank was assumed $=40 \mathrm{rpm}$.

- Mass of the reciprocating and cutting unit $=7.3 \mathrm{~kg}$.

- $\quad$ Total mass to be overcome $=(138.1$ $\times 2)+7.3$.

○ Power requirement after considering the transmission losses $(25 \%)$ as frictional loss and slippage loss, between pulley drive, eccentric arrangement for reciprocating motion, gear, etc. according to (Chandra and Kumar, 2013).

By using equation (8), under the same experimental conditions and aforementioned assumptions, it is possible to use an engine of at least 0.21 hp to operate a sliding-crank mechanism which can be applied in the design of the sugarcane stalk buds cutting unit. 


\section{Conclusion}

Overall results of this applied research can be concluded as follow:

- Cutting forces required at cane stalks bottom are often greater than that required at any other position using any blade sharpening angle.

- The maximum value of the average cutting force obtained was $134.41 \mathrm{~kg}$ at the node position and bottom of cane stalks using a blade sharpening angle of $45^{\circ}$.

- The maximum value of cutting force obtained was $138.1 \mathrm{~kg}$ at the node position and bottom of cane stalks using a blade sharpening angle of $45^{\circ}$.

It is possible to use an engine of at least $0.21 \mathrm{hp}$ to operate a sliding-crank mechanism which can be applied in the design of the sugarcane stalk buds cutting unit.

\section{References}

Abarna, R. M., Dhayanethi, A. S., Elango, M. E. and Hari, R. P. (2017), "Fabrication of sugarcane bud removal machine with advancements", International Journal of Innovation and Scientific Research, Vol. 30 No. 3, pp. 501506.

Abdel Mawla, H. A., Hemida, B. and Mahmoud, W. A. (2014 a), "Study on the mechanization of sugarcane transplanting", International Journal of Engineering and Technology

Research, Vol. 2 No. 8, pp. 237241.

Abdel Mawla, H. A., Arif, E. M., Hemayda, B. E. and Mohamed, M. E. (2014 b), "Field evaluation and crop conditions related to sugar cane mechanical harvesting", Egyptian Journal of Agricultural Research, Vol. 92 No. 1, pp. 257271.

CCSC (Central Council for Sugar Crops, 2020), World status of sugar crops, the productivity of sugar crops in Egypt, Sugar crops and sugar production in Egypt and the world, Ministry of Agriculture, Egypt, pp. $1-85$.

Chandra, S. and Kumar, P. (2013), "Design, Fabrication and Testing of Worm Sieving Machine for Commercial Production of Vermicompost", AMA, Agricultural Mechanization in Asia, Africa and Latin America, Vol. 44 No. 3, pp. 31-38.

Chang D., Kim J., Choi D., Cho KJ., Seo, T. and Kim J. (2013), "Design of a slider-crank leg mechanism for mobile hopping robotic platforms", Journal of Mechanical Science and Technology, Vol. 27 No. 1, pp. 207214.

Drees, A. M. (2005), A study on mechanization of sugar cane planting, fabricating a seedling preparation unite and performance evaluation of transplanting machine 
for sugar cane crop, Ph.D. thesis, Agricultural Mechanization Department, Faculty of Agriculture, Al-Azhar University, Egypt, pp. 3455.

Freed, R. S. P., Eisensmith, S. P., Goetez, S., Reicosky, D., Smail,V. W. and Wolberge P. (1989), Users guide to MSTAT-C, A software program for the design moorage regiment and analyses of agronomic research experiments, Michigan State University, USA.

Galal, M. O. A. (2016), "A new technique for planting sugarcane in Egypt", Institute of Integrative Omics and Applied Biotechnology Journal, Vol. 7 No. 4, pp. 15-21.

Igathinathane, C., Womac, A. R., Sokhansanj, S. and Narayan, S. (2010), "Cornstalk orientation effect on mechanical cutting", Biosystems Engineering, Vol. 107, pp. 97-106.

Mahesh, B., Chavan A., Dhaigude R., Gaikwad G. and Jadhav S. (2017), "Sugarcane Bud Cutting Machine", International Engineering Research Journal, Vol. 2 No. 8, pp. 28142816.

Mahmoud, W. A. (2016), Factors affecting the mechanical transplanting of main sugar crops, Ph.D. Thesis, Faculty of Agriculture, Al-Azhar University, Cairo, Egypt, pp. 29-43.

Mathanker, S. K., Gan H., Buss J. C., Lawson, B., Hasen A. C. and Ting,
K. C. (2015), "Power requirements and field performance in harvesting energy cane and sugarcane", Biomass and Bioenergy, Vol. 75, pp. 227-234.

Naeeni, I. P., Keshavarzi, A. and Fattahi I. (2019), "Parametric study on the geometric and kinetic aspects of the slider-crank mechanism", Iranian Journal of Science and Technology, Transactions of Mechanical Engineering, Vol. 43 No. 3, pp. 405-417.

Ragupathi, G., A., Ramesh K., Prakash V. S., Sivaprakasam, G. and Thirumoorthi E. (2017), "Design and fabrication of pneumatic sugarcane bud cutting machine", International Journal of Advanced Science and Engineering Research, Vol. 2 No. 1, pp. 413-421.

Shen, C., Chen, Q., Li Xianwang, Tian, K., Huang, J. and Zhang, B. (2014), "Experimental analysis on single stalk cutting of hemp", International Agricultural Engineering Journal, Vol. 25 No. 4, pp. 187-196.

Suraj S. M., Shubham, P. and Pankaj, B. G. (2016), "Sugarcane bud cutting machine", International Journal Innovative Research in Science \& Engineering, Vol. 2 No. 10, pp.189194.

Taghijarah H., Ahmadi H., Ghahderijani M. and Tavakoli M. (2011), "Cutting forces and energy during an impact cut of sugarcane stalks", Australian Journal of Crop Science, 
Vol. 5 No. 6, pp. 630-634.

Taghinezhad, J., Alimardani, R. and Jafari, A. (2013), "Effect of moisture content and dimensional size on the shearing characteristics of sugarcane stalks", Journal of Agricultural Technology, Vol. 9 No. 2, pp. 281294. 